\title{
Morfología vegetativa y floral, anatomía foliar y de la espina caulinar y primeros recuentos cromosómicos de Adesmia cytisoides y $A$. inflexa (Fabaceae, Papilionoideae) del Noroeste Argentino
}

\author{
Vegetative and floral morphology, leaf and caulinar thorn anatomy \\ and first chromosome counts of Adesmia cytisoides and A. inflexa \\ (Fabaceae, Papilionoideae) from Northwestern Argentina
}

D.o.I.: doi.org/10.30550/j.lil/2018.55.2/3

\author{
Caro, María S. ${ }^{1,3}$; Ana I. Ruiz ${ }^{2}$; Aldo R. Andrada1; Patricia L. Albornoz ${ }^{2,3 *}$ \\ 1 Instituto de Genética; Fundación Miguel Lillo; Miguel Lillo 251; (T4000JFE) San Miguel de Tucumán, \\ Argentina. \\ 2 Instituto de Morfología Vegetal; Fundación Miguel Lillo; Miguel Lillo 251; (T4000JFE) San Miguel de \\ Tucumán, Argentina. \\ 3 Facultad de Ciencias Naturales e Instituto Miguel Lillo (U.N.T.). Miguel Lillo 205; (T4000JFE) San \\ Miguel de Tucumán, Argentina. \\ * Autor corresponsal: albornoz@csnat.unt.edu.ar
}

\begin{abstract}
- Resumen - Adesmia cytisoides y A. inflexa (Coluteoides), son especies endémicas, arbustivas, espinosas y perennes del NOA. El objetivo de este trabajo fue caracterizar la morfología vegetativa y floral, la anatomía foliar y de la espina caulinar y determinar los números cromosómicos de ambas especies. El material vegetal fue tratado con técnicas morfológicas, anatómicas y citogenéticas convencionales. Los resultados evidencian que las especies se diferencian por el color y tamaño de la flor, número de folíolos por braquiblasto y densidad estomática; mientras que se asemejan por ausencia de cerdas pilosas en los artejos, tipo de estomas; células parenquimáticas que forman tubos con fenoles asociadas a los haces vasculares, tricomas eglandulares y glandulares, y el número cromosómico. La morfología y la anatomía de ambas especies evidencia caracteres de adaptación a ambiente xérico. La citogenética analizada es el primer aporte para la serie Coluteoides e inédita para A. cytisoides y A. inflexa.
\end{abstract}

Palabras clave: Adesmia; anatomía; cromosomas; hoja; morfología.

Abstract - Adesmia cytisoides and A. inflexa (Coluteoides) are endemic species, shrubby, thorny and perennial species from NOA. The aims of this work was to characterize the vegetative and floral morphology, leaf and caulinar thorn anatomy and determine chromosome number in both species. The plant material was treated with conventional morphological, anatomical and cytogenetic techniques. The results show that these species are differentiated by the colour and size of flowers, the number of foliole per brachyblast and stomata density,

\footnotetext{
> Ref. bibliográfica: Caro, M. S.; Ruiz, A. I.; Andrada, A. R.; Albornoz, P. L. 2018. Morfología vegetativa y floral, anatomía foliar y de la espina caulinar y primeros recuentos cromosómicos de Adesmia cytisoides y A. inflexa (Fabaceae, Papilionoideae) del Noroeste Argentino. Lilloa 55 (2): 17-29.

> Recibido: 12/09/18 - Aceptado: 16/11/18

$>$ URL de la revista: http://lilloa.lillo.org.ar

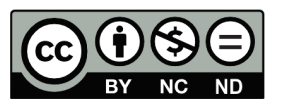

OPEn 0 ACCESS

> Algunos derechos reservados. Esta obra está bajo una Licencia Creative Commons Atribución - No Comercial - Sin Obra Derivada 4.0 Internacional.
} 
but they have the following similar traits: absence of downy hairs in the segments; type of stomata; parenchyma cells that form tubes with phenols associated to the vascular bundles; eglandular and glandular trichomes; and chromosome number. Morphology and anatomy of both species show traits of adaptation to xeric environments. The cytogenetic analyzed here is the first contribution to the series. Coluteoides but remains unpublished for $A$. cytisoides y A. inflexa.

Keywords: Adesmia; anatomy, chromosomes, leaf, morphology.

\section{INTRODUCCION}

El género Adesmia DC (Fabaceae) forma parte de la flora autóctona de la Argentina y cuenta con el mayor número de especies entre las leguminosas de dicho país (Ulibarri, 1996). La mayor riqueza específica se encuentra a lo largo de la cordillera chileno-argentina, principalmente en zonas áridas o semiáridas, entre los 900-4000 m snm (Ulibarri y Burkart, 2000). En el Noroeste Argentino (NOA) se distribuyen principalmente en las provincias fitogeográficas Prepuna y Altoandina; algunas especies pueden llegar a las provincias Chaqueña y Yunga (Ulibarri, 1996; Ulibarri y Burkart, 2000). Burkart (1967) agrupó las especies en 45 series, incluidas en dos subgéneros: Adesmia Burk. (inermes) y Acanthadesmia Burk. (espinosas). El subgénero Acanthadesmia, reconocido además por su carácter xeromórfico, comprende diversas especies arbustivas, en cojines y placas leñosas; siendo la mayoría de ellas forrajeras y utilizadas como material combustible (Burkart, 1952; Burkart, 1960; Ulibarri y Burkart, 2000). En Argentina, Acanthadesmia está representado por 6 series con un total de 54 especies. La serie Coluteoides, en el NOA, presenta dos especies endémicas arbustivas, perennes, vulgarmente conocidas como «añagua»: Adesmia cytisoides Griseb. y A. inflexa Griseb. A. cytisoides mide de 0,6 a 2 m de altura y crece en faldas montañosas subhúmedas o semisecas, entre los 2000-3000 m snm, en las provincias biogeográficas Prepuna de Catamarca, La Rioja y San Juan; Yungas de Jujuy, Salta y Tucumán y Puna de Jujuy (Burkart, 1960; Ulibarri y Burkart, 2000). Esta especie, si bien es común encontrarla, no es abundante y su distribución es disyunta según el Sistema de Información de Biodiversidad (SIB, 2017).
El estado de conservación es de preocupación menor, de acuerdo a los criterios de la Unión Internacional para la Conservación de la Naturaleza (IUCN, 2014), además de Delucchi y Hernández (2015). Burkart (1960) establece para $A$. cytisoides tres variedades, a las que considera difíciles de identificar con material de herbario debido al polimorfismo vegetativo que presenta la especie. En el presente trabajo se estudia Adesmia cytisoides var. cytisoides, descripta por Burkart (1960) por ser ésta la variedad típica de la serie.

Adesmia inflexa mide de 0,4 a $2 \mathrm{~m}$ de altura y crece entre los 1800-3700 m snm en faldas y cumbres montañosas de la provincia biogeográfica Prepuna de Salta, Catamarca y Tucumán (Ulibarri, 1985; Ulibarri y Burkart, 2000). Es un taxón que no posee variedades, común, con distribución disyunta (SIB, 2017) y su estado de conservación no fue evaluado por la IUCN (2017).

Los antecedentes referidos a la anatomía foliar de las Fabaceae-Papilionoideae fueron mencionados por Solereder (1908) y Metcalfe y Chalk (1950), quienes citan la presencia de papilas, células con taninos, proteínas o mucílago, epidermis con divisiones periclinales, tricomas glandulares y eglandulares y diferentes tipos de estomas y cristales. Metcalfe y Chalk (1950), describen la anatomía del pecíolo de las Fabaceae-Papilionoideae detallando la vascularización y establece dos grupos: haces separados o vascularización continua; mencionan células con taninos, proteínas o sustancias gomosas y cristales solitarios. Metcalfe y Chalk (1950), citan para el género Adesmia la presencia de células mucilaginosas en la epidermis foliar. Los caracteres morfológicos y anatómicos foliares y sus adaptaciones al ambiente xérico, de especies de Adesmia arbustivas espinosas, 
fueron mencionados por Burkart (1964), Pykko (1966), Ragonese (1969a, 1969b), y Caro, Ruiz y Albornoz (2016).

Desde el punto de vista citológico, los datos sobre el número cromosómico del subgénero Acanthadesmia son escasos, siendo el más frecuente $2 \mathrm{n}=2 \mathrm{x}=20$, con excepción de algunos tetraploides $2 \mathrm{n}=2 \mathrm{x}=40$ (Castronovo, 1945; Covas y Schnack, 1946; Covas, 1949; Krapovickas y Krapovickas, 1952; Rahn, 1960; Caro et al., 2016).

No se registra información acerca de las características morfológicas, anatómicas y citogenéticas de las dos únicas especies de la serie Coluteoides presentes en el NOA. Este trabajo tiene como objetivos caracterizar la morfología vegetativa y floral, la anatomía foliar y de la espina caulinar y el recuento cromosómico de $A$. cytisoides y A. inflexa, especies endémicas del NOA.

\section{MATERIALES Y MÉTODOS}

Las muestras fueron recolectadas en dos poblaciones naturales de la provincia de Catamarca y cuatro poblaciones de la provincia de Tucumán (ver detalle del material estudiado más abajo). En cada población se seleccionaron 20 individuos al azar.

Los caracteres morfológicos y reproductivos analizados fueron: hábito; presencia o ausencia de espinas; forma de las estípulas; disposición de las hojas; número, longitud, ancho y tipo de borde de los folíolos; tipo de inflorescencia; color de la flor; longitud de: lóbulo, tubo del cáliz, estambres, anteras, gineceo y semillas; longitud y ancho del estandarte; y número de óvulos.

Se trabajó con material fresco y fijado en formol-ácido acético-alcohol (FAA) (D’Ambrogio de Argüeso, 1986).

En el análisis anatómico, de cada población se seleccionaron al azar 5 individuos, y de cada individuo se tomaron, al azar, 10 hojas (5 para estudio de epidermis y 5 para cortes transversales) y 5 espinas. La arquitectura foliar se describió según Hickey (1974). Para el estudio de la epidermis foliar se diafanizaron los folíolos (Dizeo de Strittmater, 1973). En la clasificación de los tipos de estomas se utilizó la terminología propuesta por Dilcher (1974).

Mediante la técnica de «mano libre» se realizaron cortes transversales y longitudinales de lámina, pecíolo y espina (D’Ambrogio de Argüeso, 1986). Los colorantes empleados fueron cristal violeta y la doble coloración de azul astra-safranina (D'Ambrogio de Argüeso, 1986). Los preparados fueron montados en agua glicerina (1:1). Para la detección de fenoles en folíolos, pecíolos y espinas se aplicó cloruro férrico (D’Ambrogio de Argüeso, 1986). En cada muestra foliar se analizaron 5 campos ópticos (63x) y se calculó el tamaño de los estomas (longitud x latitud, $\mu \mathrm{m}$ ) y la densidad estomática (estomas $/ \mathrm{mm}^{2}$ ). El recuento cromosómico se realizó en raíces jóvenes de 5 plantas adultas pretratadas con 8 hidroquinoleina 0,002 M durante 24 hs a $4^{\circ} \mathrm{C}$, y fijadas en solución Farmer (ac. acético-etanol 3:1) por 24 hs. Los ápices fueron hidrolizados en HCL $1 \mathrm{~N}$ por $20 \mathrm{~min}$ a $60^{\circ} \mathrm{C}$ y coloreados con orceína acética al $2 \%$. Los recuentos cromosómicos se realizaron en 7 placas metafásicas.

Las observaciones se efectuaron con microscopio estereoscópico (Olympus, Japón) y óptico (Zeiss Axiostar Plus, Alemania). Las fotomicrografías se obtuvieron con cámara digital (Canon A620, Power Shot 7,1 MP y Olympus Sp-350 d 8 MP).

\section{MATERIAL ESTUdIADO}

Adesmia cytisoides: ARGENTINA. Prov. Catamarca, Dpto. Andalgalá, Cuesta a Capillitas, 27029'18"S 66²2'45"O, $2714 \mathrm{~m}$ snm, 03-III-2007, Caro 31 (LIL); 27027'53"S 66²3'46”O, 3205 m snm, 03-III-2007, Caro 32 (LIL); Prov. Tucumán, Dep. Tafí del Valle, 268'302"S 6546'590"O, 2360 m snm, 20XII-2010, Caro $S / N$ (LIL).

Adesmia inflexa: ARGENTINA. Prov. Tucumán, Dep. Tafí del Valle, Infierni1lo, 2642'17"S-6547'57'O, 2855 m snm, 29-XI-2004, Caro 11 (LIL); 2643'59,4"S65047'14,8"O, $3001 \mathrm{~m}$ snm, 13-V-2014, Caro 129 (LIL); Los Corpitos 26³8'27,84"S6549'19,62”O, 2631 m snm, 24-XI-2015, Caro 136 (LIL). 


\section{RESULTADOS}

\section{CARACTERÍSTICAS MORFOLÓGICAS}

Adesmia cytisoides y A. inflexa son arbustos, perennes, con espinas pseudo-dicotómicamente ramificadas. Las diferencias morfológicas entre las especies se detallan en la Tabla 1. Las espinas terminales de A. cytisoides pueden ser estériles o fértiles, con el eje central florífero (Fig. 1A); mientras que, en A. inflexa son completamente estériles (Fig. 2A). La pubescencia en ambas especies es variable, en general $A$. cytisoides es pubescente y $A$. inflexa glabra, o con pubescencia solo en las partes jóvenes de hojas y tallos. Ambas especies presentan hojas paripinnadas (raro imparipinnadas) sobre braquiblastos con número y tamaño de folíolos variable, de 5-12 pares con una longitud de 2-10 $\mathrm{mm}$ y nervio medio prominente en $A$. cytisoides; y de 4-8 pares con una longitud de 1-3 mm y nervio medio incluído en $A$. inflexa. Los foliolos de ambas especies son ovados con bordes enteros, raramente con un diente lateral que porta una o dos sétulas glandulosas (Figs. 1B; 2B). Estípulas triangulares, pubescentes en la superficie abaxial, ciliadas y soldadas entre sí en $A$. cytisoides (Fig. 1C); mientras que, en $A$. inflexa presentan bordes escariosos, glabras, casi libres entre sí (Fig. 2C). El tipo de inflorescencia y la morfología floral son diferentes entre ambas especies. A. cytisoides presenta inflorescencia racemosa, con flores de corola amarilla grande de $1-2 \mathrm{~cm}$ de longitud (Fig. 1D); cáliz pubescente, pentadentado, con dientes triangulares alargados (Fig. 1E); estandarte amplio, mucronado, de 8-10 mm de longitud x 6-12 mm de ancho, pubescente exteriormente y en el interior de la uña (Fig. 1F); alas glabras, ciliadas en el margen inferior y parte media (Fig. 1G); quilla ancha glabra excepto el margen inferior ciliado (Fig. 1H). La inflorescencia en A. inflexa es en umbela, con flores de corola anaranjada, pequeñas de 0,5- 0,8 cm de longitud (Fig. 2D); cáliz campanulado, glabro, con 5 lóbulos triangulares breves (Fig. 2E); estandarte reflejo, de 4-5 $\mathrm{mm}$ de longitud $\mathrm{x}$ 5-6 mm de ancho; uña provista de un mechón de pelos denso (Fig. 2F); alas glabras, obtusas (Fig. 2G); quilla incurva (Fig. 2H). Ambas especies presentan 10 estambres en dos ciclos de 5 estambres cada uno, con dos superiores geniculados, la longitud en $A$. cytisoides es de 11-13 mm (Fig. 1I); mientras que en $A$. inflexa es de 5-7 mm (Fig. 2I); anteras uniformes de 3-6 mm de longitud, dorsifijas; gineceo de 13-17 mm de longitud en A. cytisoides (Fig. 1J), y 7-8 mm de longitud en $A$. inflexa (Fig. 2J), presentando ambas especies ovario lineal, pubescente, estilo incurvo, glabro y estigma capitado. El fruto de ambas especies es un lomento incurvo con 1-4 artejos no muricados y sin cerdas pilosas, semicirculares subplanos, $A$. cytisoides presenta artejos pubescentes (Fig. 1K); mientras que, en $A$. inflexa son glabros (Fig. $2 \mathrm{~K}$ ). La morfología de la semilla de $A$. cytisoides y $A$. inflexa es similar, siendo arriñonada, aplanada de aproximadamente $2-3 \mathrm{~mm}$ de longitud x 2-3mm de ancho (Figs. 1L, 2L).

\section{ARQUITECTURA FOLIOLAR}

La arquitectura foliolar de Adesmia cytisoides y $A$. inflexa es semejante. La lámina es entera, simétrica, de forma obovada ancha, ápice mucronado a emarginado, de base aguda normal, margen entero (Figs. 3A, 3B) y textura cartácea. Ocasionalmente, folíolos con sétula cercana al ápice de la lámina (Fig. 3B). Lámina con venación pinnada, camptódroma, broquidódroma. La vena primaria es de tamaño fuerte y recorrido derecho. Las venas secundarias de grosor moderado, con ángulo de divergencia agudo-moderado, de recorrido curvado uniéndose a secundarias superadyacentes en ángulo agudo (Figs. 3A, 3B). Venas intersecundarias compuestas (Fig. 3A). Venas terciarias de modelo reticulado al azar. Areolas de desarrollo imperfecto, sin vénulas, con vénulas simples lineares o curvadas, o ramificadas una o dos veces (Figs. 3C, 3D).

\section{ANATOMÍA DEL FOLÍOLO}

La anatomía foliolar de ambas especies es similar. En vista superficial ambas epidermis presentan células isodiamétricas a poligonales con paredes lobuladas, con cutícula le- 


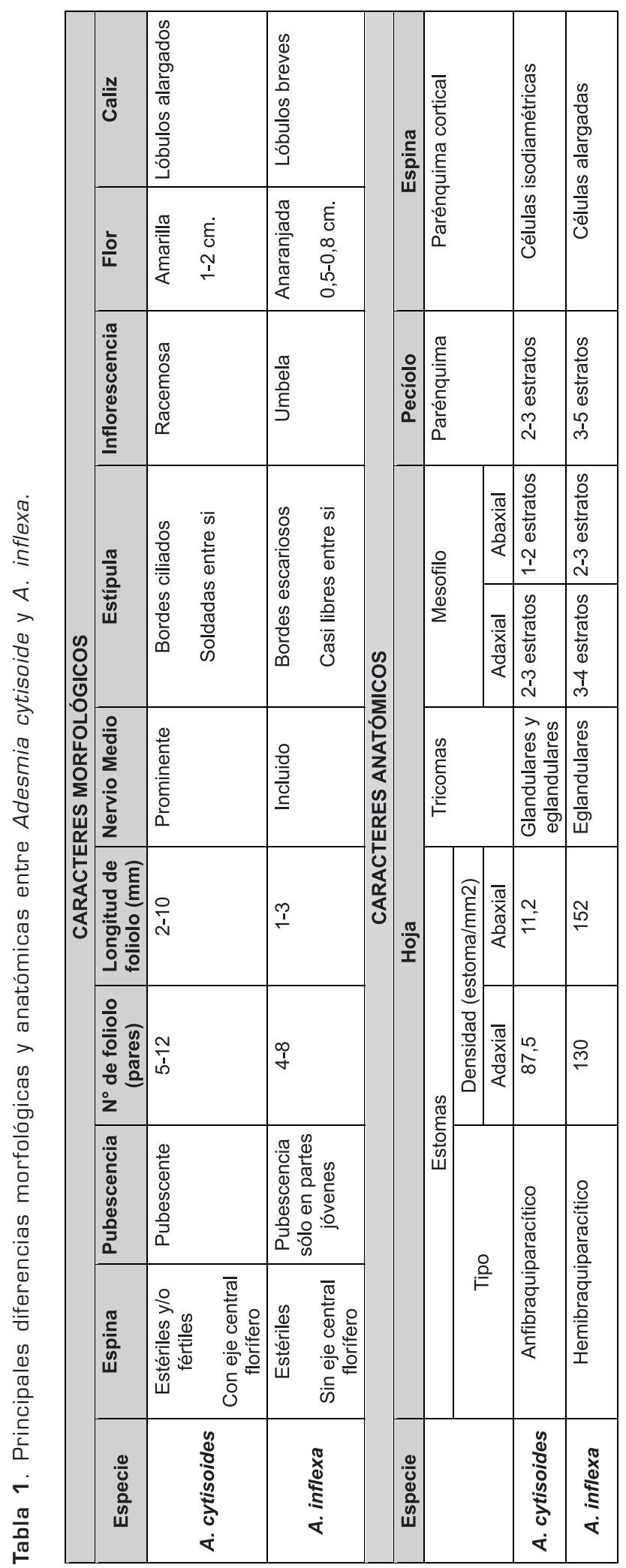




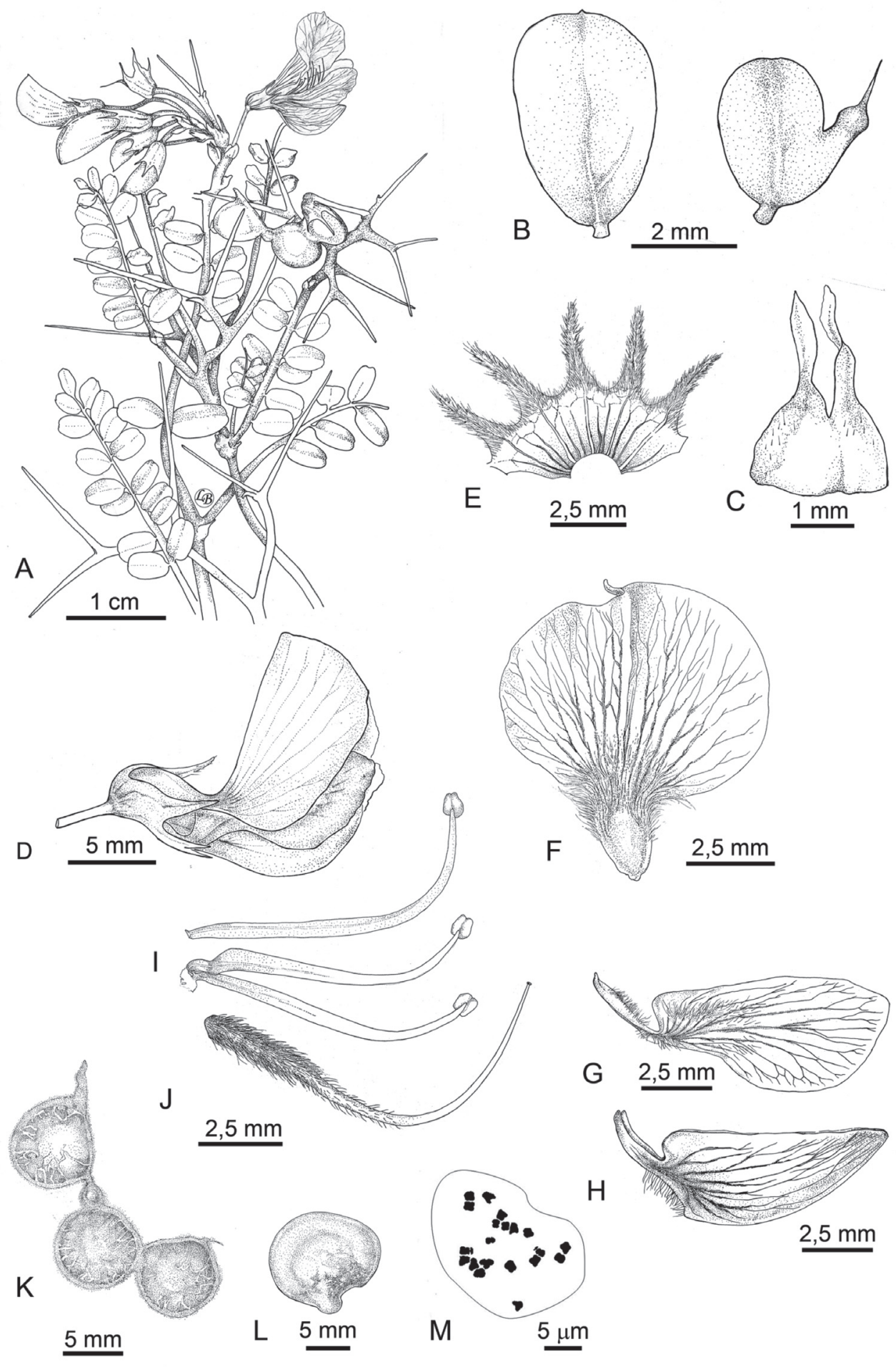

Fig. 1. Adesmia cytisoides. Morfología. A) Aspecto general de la planta. B) Folíolos. C) Estípula. DJ Flor. E) Cáliz. FJ Estandarte. G] Ala. H) Quilla. I) Estambres. J) Gineceo. K) Fruto. L) Semilla. M) Número cromosómico 2n= 20. Caro 32 (LIL). 


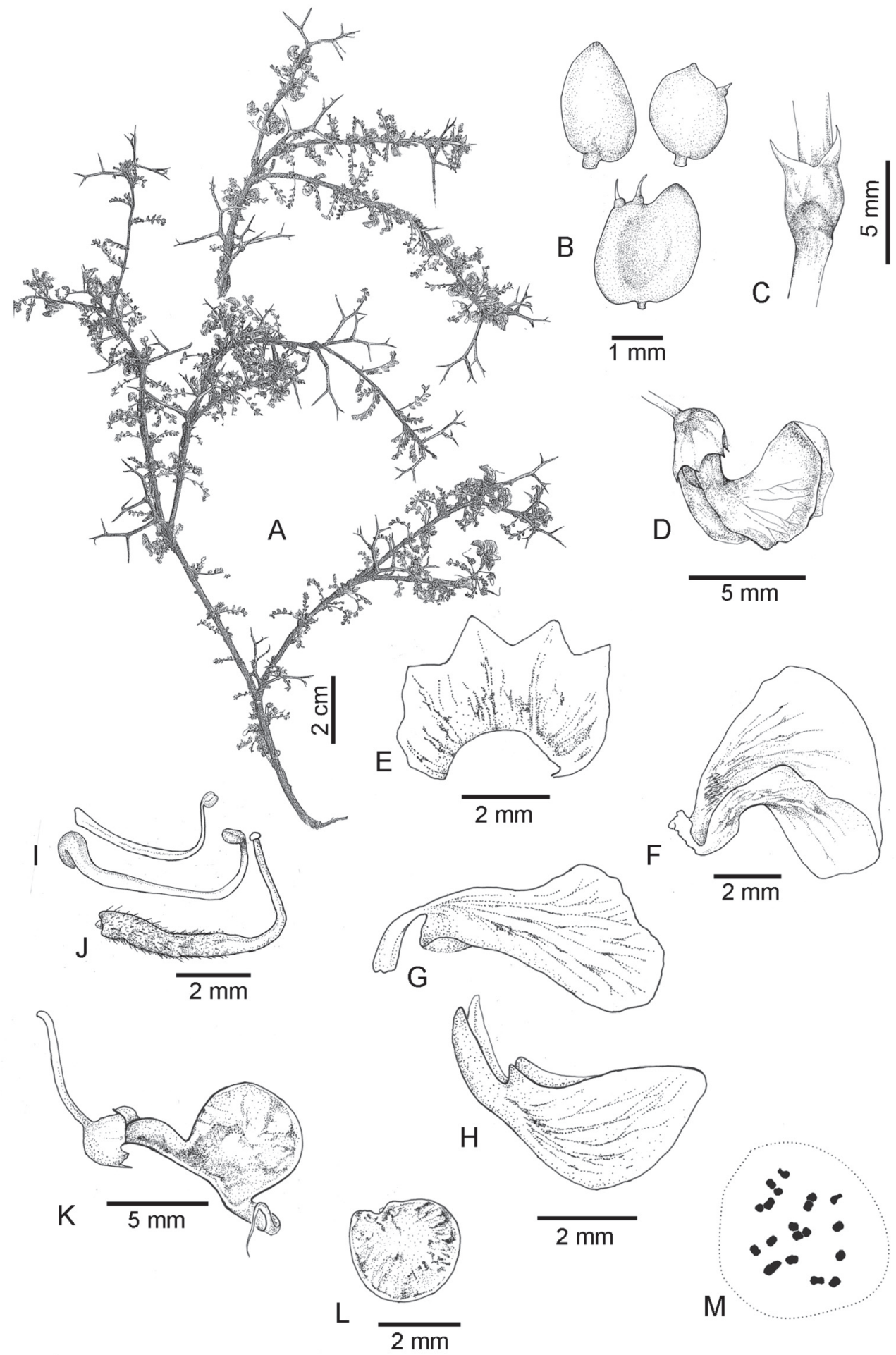

Fig. 2. Adesmia inflexa. Morfología. A) Aspecto general de la planta. B) Folíolos. C) Estípula. D) Flor. E) Cáliz. FJ Estandarte. G] Ala. H) Quilla. I] Estambres. J) Gineceo. KJ Fruto. LJ Semilla. M) Número cromosómico 2n=20. Caro 136 (LIL). 
vemente estriada (Figs. 3E, 3F). Los folíolos son anfistomáticos y comparten 4 tipos de estomas: anomocítico, actinocítico (Fig. 3F), braquiparacítico (Fig. 3G), ciclocítico (Fig. $3 \mathrm{H})$; A. cytisoides presenta además el tipo anfibraquiparacítico (Fig. 3I) y A. inflexa hemibraquiparacítico. Se observan estomas gemelos. En relación al tamaño de las células oclusivas, $A$. cytisoides poseen una longitud promedio de $25 \mu \mathrm{m}( \pm 2,0)$ y una latitud de $17 \mu \mathrm{m}( \pm 1,5)$, la densidad estomática es de 87,5 estomas $/ \mathrm{mm}^{2}$ y 111,2 estomas $/ \mathrm{mm}^{2}$ en la epidermis adaxial y abaxial respectivamente; mientras que, en $A$. inflexa el tamaño es de $24 \mu \mathrm{m}( \pm 2,0)$ de longitud y $19 \mu \mathrm{m}$ $( \pm 1,2)$ de latitud, la densidad estomática es de 130 estomas $/ \mathrm{mm}^{2}$ y 152 estomas $/ \mathrm{mm}^{2}$ en superficie adaxial y abaxial respectivamente. A. cytisoides presenta en ambas epidermis dos tipos de tricomas: eglandulares y glandulares. Los primeros son tricelulares, uniseriados, adpresos y antrorsos; la célula de inserción a la epidermis es redondeada, la célula central es corta y rectangular y la célula terminal es larga de extremo aguzado, pared gruesa y cutícula lisa (Fig. 3J); son más numerosos a la altura del nervio medio en la superficie abaxial. En la base de estos tricomas, las células epidérmicas se disponen en roseta. Los tricomas glandulares son pluricelulares, con una glándula en el extremo distal (Fig. 3K). A. inflexa presenta en ambas epidermis tricomas eglandulares idénticos a los descriptos para A. cytisoides.

La lámina de las especies estudiadas, en corte transversal, es plana (Fig. 3L), con cutícula gruesa de 3 a $4 \mu \mathrm{m}$ de espesor (Fig. 4A). Ambas epidermis evidencian divisiones periclinales que originan una epidermis pluristrata 2 (3) capas, con células de paredes gruesas (Fig. 4A). Los estomas se observan al mismo nivel que las células epidérmicas, con importantes cámaras subestomáticas (Fig. 4A). El mesofilo es equilateral, en $A$. cytisoides el parénquima en empalizada adaxial posee 2-3 estratos y el abaxial de 1-2 estrato; mientras que, en $A$. inflexa aumenta el número de estratos (3-4 adaxial, 2-3 abaxial) (Figs. 4A, 4B). Entre ambos tejidos se encuentra el parénquima esponjoso de
1-2 estratos de células (Fig. 4B). Los haces vasculares son colaterales rodeados por una vaina parenquimática, algunas de estas células son de mayor tamaño y se organizan en tubos que contienen fenoles (Figs. 4C, 4D, 4E). Los caracteres de la anatomía foliolar que permiten diferenciar ambas especies se detallan en la Tabla 1.

\section{ANATOMÍA DEL PECÍOLO}

Las especies estudiadas presentan similitud en la estructura anatómica del pecíolo. En vista superficial ambas epidermis poseen células poligonales alargadas con el eje mayor paralelo al eje mayor del pecíolo, con paredes rectas y cutícula lisa (Fig. 5A), con abundantes tricomas eglandulares y glandulares, idénticos a los descriptos para la lámina.

En corte transversal es subcircular con escotadura adaxial (Fig. 5B). La epidermis es pluristrata, semejante a la del folíolo. La corteza está formada por células parenquimáticas en empalizada de 2 (3) estratos en A. cytisoides, mientras que en $A$. inflexa de 3 4 (5) estratos (Fig. 5B). El sistema vascular presenta 5 (6) haces colaterales, inmersos en parénquima; ubicándose 3 de mayor tamaño en posición central (Fig. 5B). Casquetes de fibras se observan hacia floema (Fig. 5C). Numerosos tubos fenólicos se disponen próximos a la vascularización (Figs. 5B, 5C). Los caracteres de la anatomía del pecíolo que permiten diferenciar ambas especies se detallan en la Tabla 1.

\section{ANATOMÍA DE LA ESPINA CAULINAR}

Ambas especies presentan similitud en la histología de la espina. En vista superficial la epidermis está formada por células poligonales de paredes rectas y cutícula lisa, semejante a lo observado en pecíolo. Presenta estomas y escasos tricomas, idénticos a los descriptos para lámina y pecíolo.

En corte transversal la espina es circular con crecimiento secundario temprano (Fig. 5D) debido al meristema cambial continuo. La epidermis es pluristrata con paredes gruesas. Internamente se continúa con 6-7 capas 

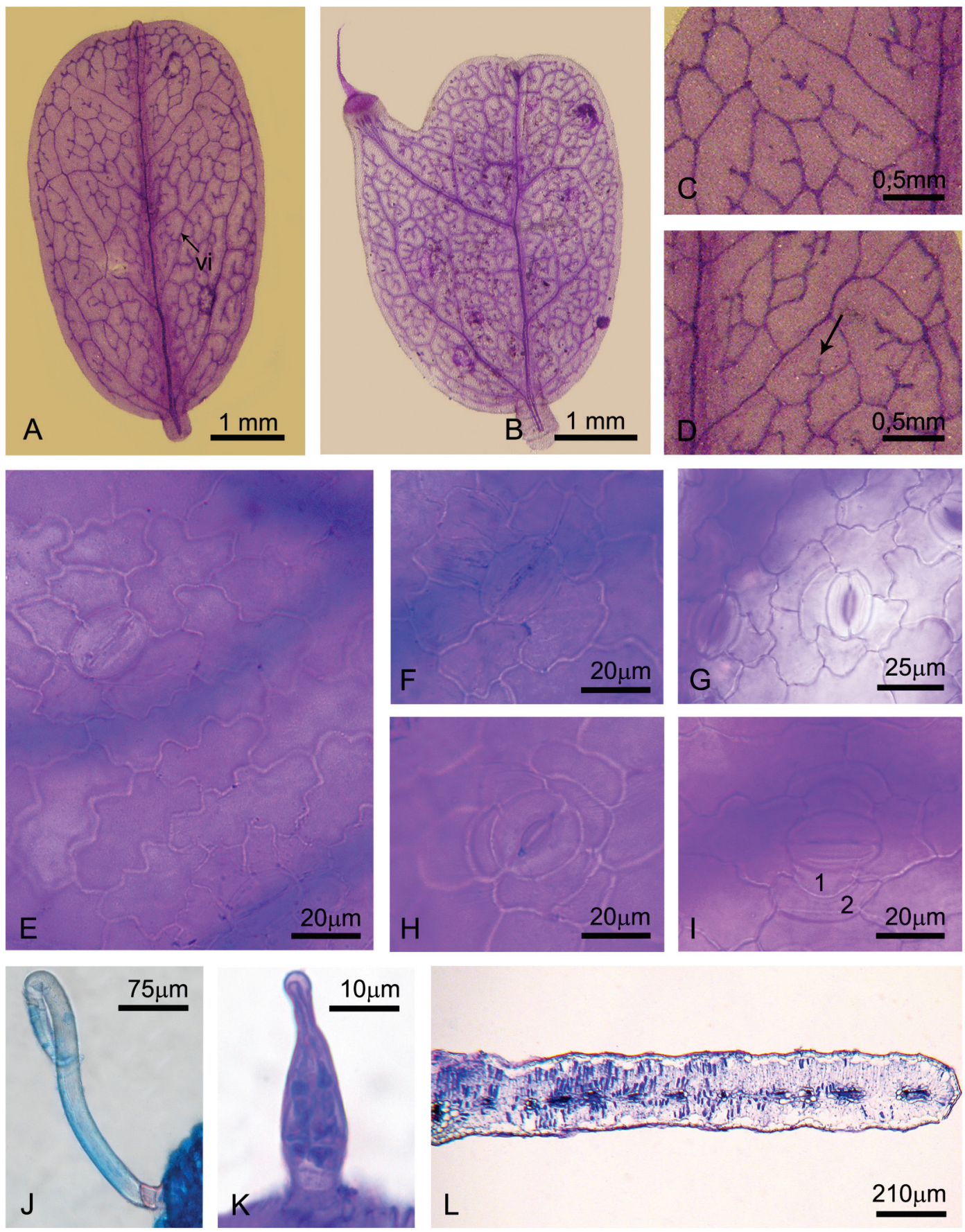

Fig. 3. Adesmia cytisoides y A. inflexa. Arquitectura y anatomía del folíolo. A-D) Arquitectura del folíolo. A] Folíolo mucronado. B] Folíolo emarginado con sétula. C) Areolas sin vénulas, con vénulas simples lineares o curvadas ramificadas dos veces. D) Detalle de areola con vénula ramificada una vez (flecha). E-L) Anatomía del folíolo. E) Epidermis adaxial en vista paradermal. F) Estoma actinocítico. G) Estoma braquiparacítico. H) Estoma ciclocítico. I) Estoma anfibraquiparacítico (1,2, células subsidiarias). J) Tricoma eglandular tricelular. K) Tricoma glandular pluricelular. L) Corte transversal. Referencias: vi, vena intersecundaria. Caro 32 (LIL), Caro 136 (LIL). A-D, I, K, L: A. cytisoides. E-H, J: A. inflexa. 

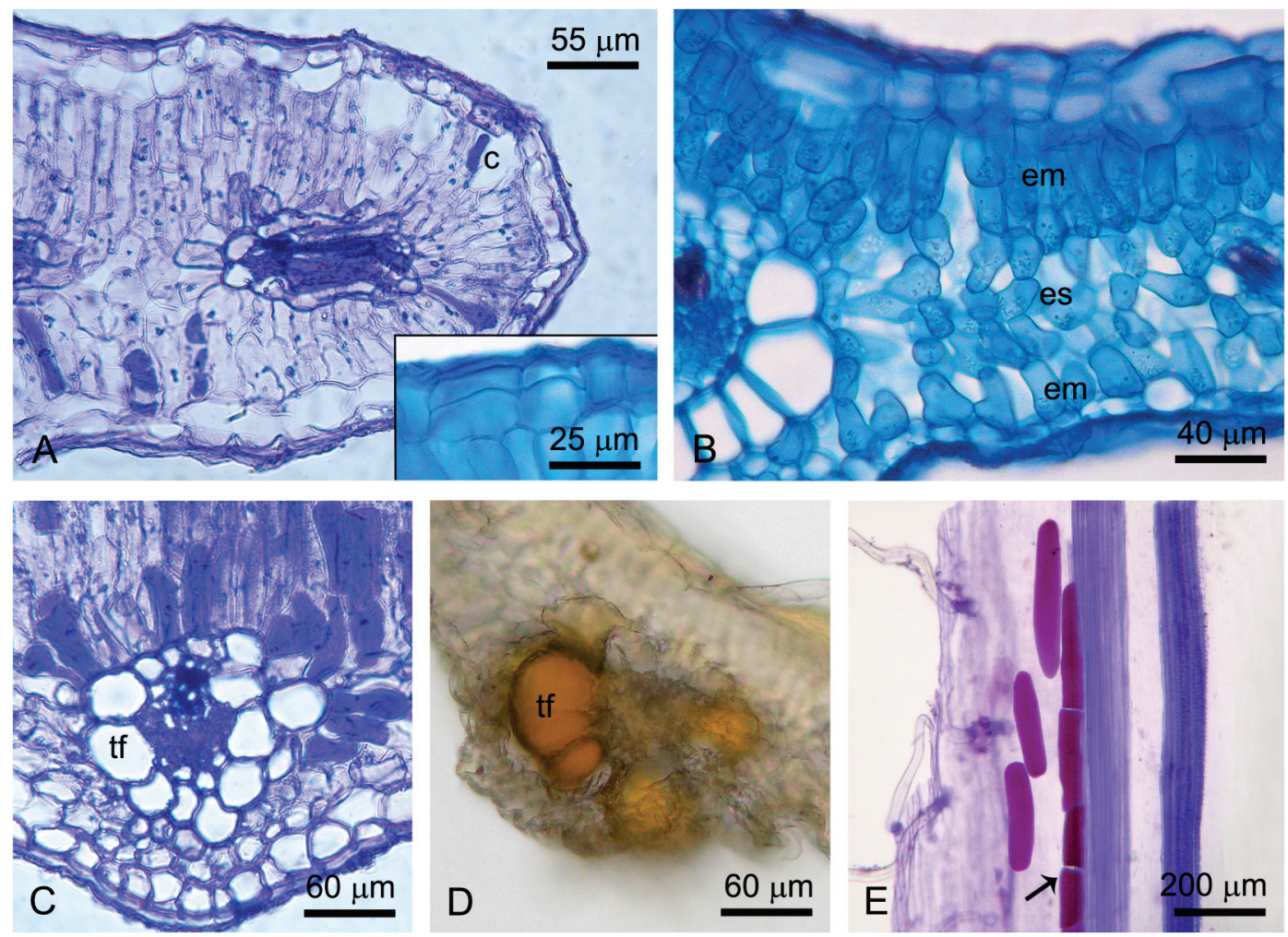

Fig. 4. Adesmia cytisoides y A. inflexa. Anatomía del folíolo. A-E) Corte transversal. A] Epidermis pluristrata, posición de estomas y cámaras subestomáticas, en imagen incluida epidermis en división periclinal. B] Mesofilo equilateral. C) Haz vascular colateral de vena primaria. D) Test de fenol positivo. E) Corte longitudinal con tubos fenólicos. Referencias: c, cámara subestomática; em, parénquima en empalizada; es, parénquima esponjoso; tf, tubos fenólicos. Caro 32 (LIL), Caro 136 (LIL). A, B: A. inflexa. C-E: A. cytisoides.

de parénquima cortical, este tejido en $A$. cytisoides presenta células isodiamétricas, mientras que en $A$. inflexa son levemente alargadas a isodiamétricas. Los últimos estratos de la corteza (1-3) forman tubos fenólicos. Floema y xilema continuos por la actividad del cámbium, formando una estela de tipo protostela. Esclerénquima discontínuo, formado por fibras, asociado al floema (Fig. 5D). Médula parenquimática en posición central, con tubos fenólicos. Los caracteres anatómicos de la espina caulinar que permiten diferenciar ambas especies se detallan en la Tabla 1.

\section{EsTUDIO CITOLÓGICO}

El número cromosómico obtenido para las dos especies estudiadas es $2 n=20$, con cromosomas pequeños, cuyas longitudes varían de 1-2 $\mu \mathrm{m}$ (Fig. $1 \mathrm{M} ; 2 \mathrm{M}$ ).

\section{DISCUSIÓN Y CONCLUSIONES}

En el presente trabajo se da a conocer las características morfológicas vegetativa y floral, la anatomía foliar y de la espina caulinar y el recuento cromosómico de Adesmia cytisoides y A. inflexa. Ambas especies se reconocen a campo por ser arbustos espinosos que presentan frutos con artejos sin cerdas pilosas, la variedad típica de $A$. cytisoides se caracteriza por la presencia de grandes flores amarillas a diferencia de $A$. inflexa cuyas flores son pequeñas y anaranjadas en concordancia con lo descripto por Ulibarri (1985). 

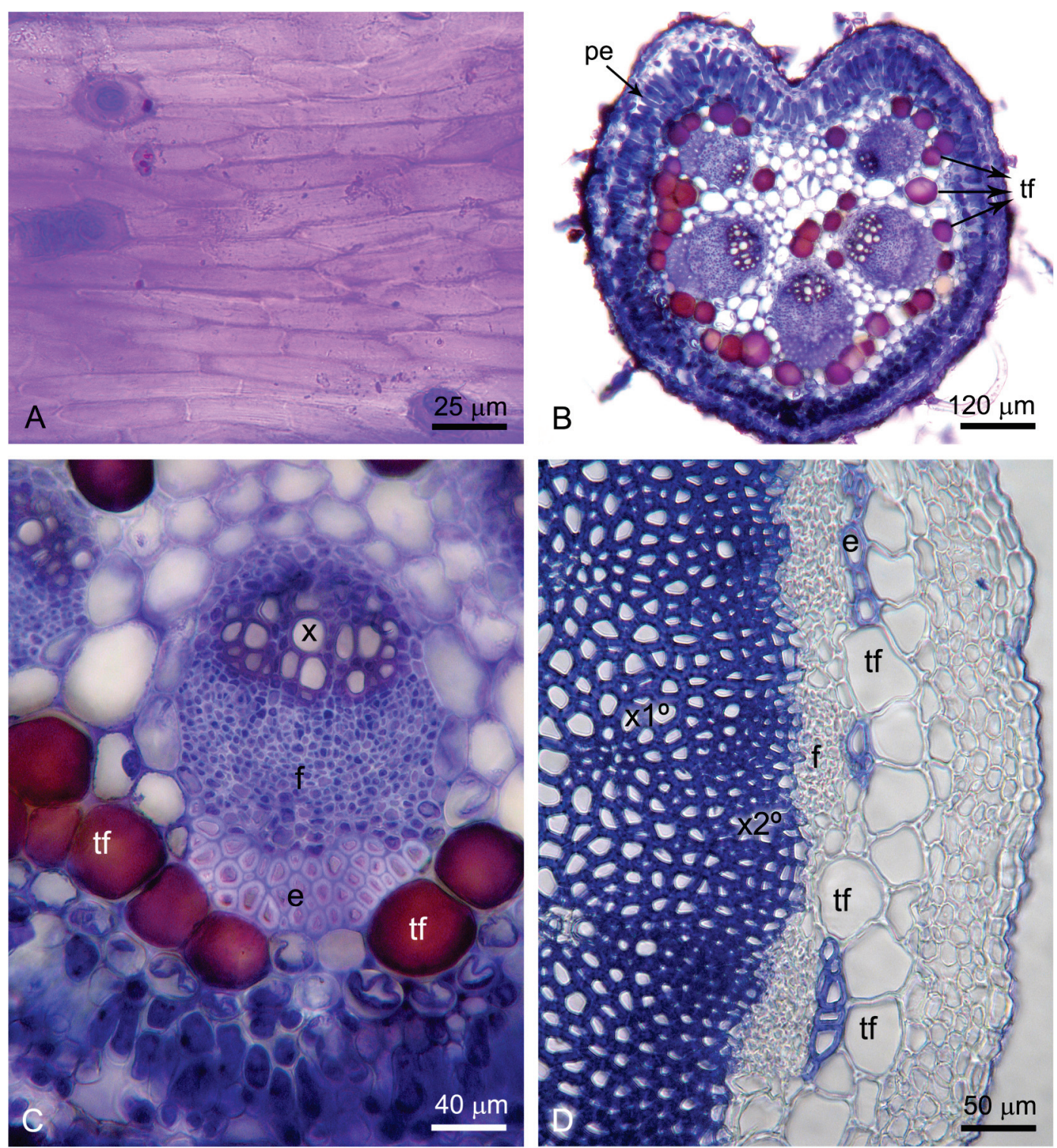

Fig. 5. Adesmia cytisoides y A. inflexa. Anatomía del pecíolo y la espina caulinar. A-C) Anatomía de pecíolo. A] Epidermis en vista superficial. B) Corte transversal, C) Detalle de haz vascular y tubos fenólicos. D) Corte transversal de espina caulinar. Referencias: e, esclerénquima; f,

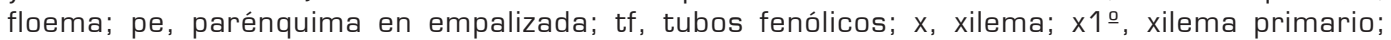
x2o, xilema secundario. Caro 32 (LIL), Caro 136 (LIL). A-C: A. inflexa. D: A. cytisoides.

En relación a la anatomía, Solereder (1908) y Metcalfe y Chalk (1950), citan para las Fabaceae-Papilionoideae la presencia de diferentes tipos de estomas, células tánicas, tricomas eglandulares y glandulares. Las especies evaluadas evidenciaron las mismas estructuras descriptas por los autores antes mencionados. Los tipos de estomas encontrados fueron anomocítico, actinocítico, braquiparacítico, ciclocítico, anfibraquiparacítico y hemibraquiparacítico; células parenquimáticas que forman tubos con fenoles se encuentran asociadas a la vascularización; los tricomas son de tipo eglandular y glandular. 
La densidad estomática de estas especies es baja en comparación con las plantas xerófitas, esto respondería al ambiente en el que habitan (transición entre yunga y prepuna). Metcalfe y Chalk (1950) citan para el género Adesmia la presencia de células mucilaginosas en la epidermis foliar, las cuales no fueron registradas en las especies estudiadas. Los mismos autores, en cuanto a la vascularización del pecíolo establecen dos grupos: haces separados o vascularización continua. Los taxones aquí analizados presentaron 5 a 6 haces vasculares.

La morfología y la anatomía de $A$. cytisoides y $A$. inflexa revela caracteres que se corresponden con adaptación a ambientes xéricos: plantas arbustivas, microfila, espinas caulinares, pubescencia, cutícula gruesa, mesofilo equilateral, estomas en ambas epidermis y presencia de fenoles; caracteres similares fueron citados por Pykko (1966) para A. patagónica y Caro et al. (2016) para A schickendanzii. En relación a las espinas caulinares, este mismo autor las describe con abundante esclerénquima en posición medular, mucílago y fenoles en parénquima cortical; a diferencia de las espinas aquí estudiadas las que evidenciaron escaso esclerénquima limitado a casquetes en el floema y fenoles en el parénquima medular.

Los resultados citogenéticos constituyen el primer aporte para la serie Coluteoides y son inéditos para $A$. cytisoides y $A$. inflexa con número cromosómico $2 n=2 x=20$, siendo estas especies diploides. Este registro concuerda con lo reportado por Castronovo (1945), Covas y Schnack (1946), Covas (1949), Krapovickas y Krapovickas (1952), Rahn (1960) y Caro et al. (2016) para la mayoría de las especies del subgénero Acanthadesmia.

Ambas especies aquí estudiadas se asemejan por: tipo de venación, la presencia de fenoles y la dotación cromosómica.

Los caracteres de valor diagnóstico para la identificación de las especies estudiadas son: tamaño y color de la flor, número de folíolos por braquiblasto, densidad estomática, tipo de estomas y tricomas.

\section{AGRADECIMIENTO}

Agradecemos a la Lic. Lelia Bordón de la sección Iconografía (FML), por la realización de los dibujos y las láminas de este trabajo.

\section{BIBLIOGRAFÍA}

Burkart, A. (1952). Las Leguminosas Argentinas silvestres y cultivadas. Acme Agency, Sociedad de Responsabilidad Limitada.

Burkart, A. (1960).Contribución al estudio del género Adesmia (Leguminosae). III. Darwiniana 12 (1): 81-138.

Burkart, A. (1964).Contribución al estudio del género Adesmia (Leguminosae). V. Darwiniana 13: 9-66.

Burkart, A. (1967). Sinopsis del género sudamericano de Leguminosas Adesmia DC. Contribución al estudio del género Adesmia VII. Darwiniana 14: 463-568.

Caro, M. S., Ruiz, A. I., Albornoz, P. L. (2016). Exomorfología, anatomía vegetativa y citología de Adesmia schickendanzii (Fabaceae-Papilionoideae) del Noroeste argentino. Lilloa 53 (1): 3-11.

Castronovo, A. (1945). Estudio cariológico de doce especies de leguminosas argentinas. Darwiniana 7 (1): 38-57.

Covas, G. (1949). Estudios cariológicos en Antofitas. III. Darwiniana 9 (1): 158162.

Covas, G., Schnack, B. (1946). Número de cromosomas en antofitas de la región del Cuyo (República Argentina). Revista Argentina de Agronomía 13 (3): 153166.

D’Ambrogio de Argüeso, A. (1986). Manual de Técnicas en Histología Vegetal. Hemisferio Sur S. A., Buenos Aires.

Delucchi, G., Hernández, M. P. (2015). Leguminosas amenazadas de la Argentina: criterios para categorizar su grado de amenaza. Historia Natural (tercera serie) 5 (2): 107-120.

Dilcher, D. L. (1974). Approaches to the identification of angiosperm leaves. The Botanical Review 40: 1-157.

Dizeo de Strittmater, C. G. (1973). Nueva técnica de diafanización. Boletín de la Sociedad Argentina de Botánica 15:126129.

Hickey, L. J. (1974). Clasificación de la arquitectura de las hojas de Dicotiledóneas. Boletín de la Sociedad Argentina de Botánica 16: 1-26.

Krapovickas, A., Krapovickas, A. M. F. (1952). Notas citológicas sobre leguminosas. Darwiniana 9 (3-4): 612-613. 
Metcalfe, C. R., Chalk, L. C. (1950). Anatomy of the Dicotyledons. Clarendon Press, Oxford.

Pykko, M. (1966). The leaf anatomy of East Patagoniac xeromorphic plants. Annales Botanici Fenici 3 [4]:490-1.

Ragonese, A. M. (1969a). Vascularización de la base foliar y pecíolo de algunas especies de Adesmia. Darwiniana 15: 143-149.

Ragonese, A. M. (1969b). Anatomía del género Adesmia (Leguminosas). Darwiniana 15: 150-182.

Rahn, K. (1960). Chromosome numbers in some South American Angiosperms. Botanisk Tidsskrift 56 (2): 117-127.

SIB, 2017. Sistema de Información de Biodiversidad Administración de Parques Nacionales. Recuperado de http://www. sib.gov.ar.
Solereder, H. (1908). Systematic anatomy of the Dicotyledons. Oxford at the Clarendon Press, London.

IUCN, 2014. The IUCN red list of threatened species. Versión 2. Recuperado de http:// www.iucnredlist.org.

IUCN, 2017. The IUCN red list of threatened species .Versión 2. Recuperado de http://www. iucnredlist.org.

Ulibarri, E. A. (1985). Aclaración sobre el tipo de Adesmia inflexa Griseb. y su sinonimia (Leguminosae-Papilionoideae). Darwiniana 26 (1-4): 285-287.

Ulibarri, E. A. (1996). Fabaceae Lindley Tribu 10. Adesmiae (Benth.) Hutchinson. Flora del Valle de Lerma. Aportes Botánicos de Salta (Argentina), Serie Flora 4 (8): $1-11$.

Ulibarri, E. A., Burkart, A. (2000). Sinopsis de las especies de Adesmia de la Argentina. Darwiniana 38: 9-126. 